\title{
Multivariate Analysis Approach on the Study of Quality of Life: A Case Study in Some Towns of Amhara Regional State, Ethiopia
}

\author{
Genanew Timerga Neri ${ }^{1}$, Nigatu Degu Terye ${ }^{2}$, Haymanot Zeleke Tadesse ${ }^{1}$, \\ Woldesadik Kagnew Abebaw ${ }^{3}$, Tena Manaye Endalamaw ${ }^{1}$ \\ ${ }^{1}$ Department of Statistics, Debre Birhane University, Debre Birhane, Ethiopia \\ ${ }^{2}$ Department of Statistics, Hawassa University, Hawassa, Ethiopia \\ ${ }^{3}$ Department of Marketing Managment, Debre Birhane University, Debre Birhane, Ethiopia
}

\section{Email address:}

tichdar@gmail.com (G. T. Neri),ndegu9@gmail.com (N. D. Terye), haymiezt@gmail.com (H. Z. Tadesse), woldkagn@gmail.com (W. K. Abebaw), tenamanaye@gmail.com (T. M. Endalamaw)

\section{To cite this article:}

Genanew Timerga Neri, Nigatu Degu Terye, Haymanot Zeleke Tadesse, Woldesadik Kagnew Abebaw, Tena Manaye Endalamaw. Multivariate Analysis Approach on the Study of Quality of Life: A Case Study in Some Towns of Amhara Regional State, Ethiopia. American Journal of Theoretical and Applied Statistics. Vol. 4, No. 6, 2015, pp. 587-601. doi: 10.11648/j.ajtas.20150406.31

\begin{abstract}
Quality of life (QOL) is gaining interest from a variety of disciplines and important tool for policy evaluation, rating of cities, urban planning and management. Cities are the center of economy, politics, commerce and other activities, so very necessary to analyze the conditions that contribute to the quality of urban life. This study identifies the factors that affect QOL of the people in the region. 809 household heads were selected based on stratified random sampling method. Different statistical methods have been used to analyze the primary data. Factor analysis is used to reduce the number of dimensions of both subjective and objective quality of life into few, which are unrelated to each other. Binary logistic regressions and ordinal logistic regressions are also applied to identify the most significant factors that can affect quality of life in the region. The principal component analysis revealed that 6 dimensions of QOL were extracted from 20 subjective attributes; namely; housing, economic, environmental, neighborhood safety and security, social connectedness and quality of public service. Binary logistic regression model shows all of the dimensions are significantly related to QOL. Factor analysis extract 6 factors using 15 objective attributes, namely; socio-economic, access to public service, access to education, housing, religion and length of residency are found to significant predictor of QOL in objective dimensions of the region. Religion and length of residence have positive impact and other have negative contribution to QOL. Results of this study can be used in designing future urban QOL studies in the region.
\end{abstract}

Keywords: Subjective, Objective, Ordinal Regression, QOL, Factor Analysis

\section{Introduction}

Quality of life (QOL) is gaining interest from a variety of disciplines such as planning, behavioral medicine, marketing and management and is becoming an important tool for policy evaluation, rating of places, urban planning and management.

The term "quality of life" is used to indicate the general well-being of people and societies. It is often associated with the term "standard of living" but the two do not necessarily mean the same. A standard of living merely is the evaluation of the wealth and employment status of a person in a society. Though both are factors to determine quality of life, these are not its sole indicator. A person's environment, physical and mental health, education, recreation, social well-being, freedom, human rights and happiness are also significant factors.

Quality of life can be measured objectively or subjectively. Objectively, quality of life is measured using objective indicators which are related to observable facts that are derived from secondary data. Example of secondary data include population density, crime rate, level of education, unemployment rate, household income, traffic accident, house hold characteristics etc.

Subjectively, quality of life is measured by using subjective indicators which tries to measure and quantify the citizen's satisfaction from the urban welfare. For instance satisfaction of people from health care accessibility, satisfaction from 
access to job, satisfaction of urban security or satisfaction from access to housing, satisfaction toward cost of living etc. Using both objective and subjective measures of quality of life, previous studies have examined the association between the two.

The concept of quality of life is complex, not easily defined in agreeable terms and not much studied in the Ethiopian context. In the Ethiopian context quality of life mainly refers to the availability of resources and goals to satisfy basic needs [16]. According to [2], people's satisfaction on their life has to do with having farm land, cattle, farm implements and a house in rural settings. It is having some job (employment) or business (some income) in the urban setting. As few studies are available on quality of life in Ethiopia, this study intends to fill this gap with focus on selected zones of Amhara region.

Thus in this study, the quality of life of the people in the region is measured by using both subjective and objective attributes. From the perspective of urban planners, cities/towns are the center of economy, politics, commerce and other activities. So it is necessary to analyze the conditions that contribute to the quality of urban life. Based on this, quality of life people in many regions of developing countries are not clearly identified. Thus this study aims to address the following questions

1. What factors affect resident's quality of life in selected Zone towns/cites in the region?

2. What are the dimensions of the quality of life for both subjective and objective aspects?

Objectives of the study

The general objective of the study is to assess the factors that affect quality of life of people in selected towns.

Specific objectives are:

- To identify the relationship between domains and attributes of each domains of quality of life.

- To determine the factors that influences quality of life in selected Zones towns.

- To identify the dimensions of both subjective and objective quality of life of the people in selected Zone towns.

- To compare subjective and objective quality of life of selected Zone towns.

- To provide relevant information to the concerned body about the peoples quality of life in region and to recommend on the possible solutions.

\section{Materials and Methods}

Sampling technique This study has been conducted in selected Zone towns, in Amhara National Regional State (ANRS), Ethiopia from November 2013 to June 2014. The ANRS administration has divided into eleven different zones. We have used cross-sectional data analysis by stratified and systematic random sampling was adopted. A stratified random sampling technique is a method of sampling, which involves the division of a population into smaller groups, known as strata in such a way that individuals in the same strata are assumed to be homogenous with respect to some characteristics. Then residential houses from each kebele will selected by using systematic random sampling and finally one individual in each selected residential house was required to fill the questionnaire.

Sample size determination Determining the adequate sample size was the most important decision that faces the researcher. Usually sample size determined based on the sampling technique, stratified random sampling was used and sample size determination formula that adopted in this study was [10]

$$
n=\frac{\sum_{i=1}^{k} \frac{N_{i}^{2} p(1-p)}{w_{i}}}{\frac{N^{2} e^{2}}{Z^{2}}+N p(1-p)}
$$

Where, $\mathrm{n}$ stands for the sample size needed

$\mathrm{N}$ is the total number of household in towns of selected zones.

$\mathrm{Z}$ is the inverse of the standard normal cumulative distribution that

Correspond to the level of confidence $(Z=1.96)$

$\mathrm{K}$ is the total number of strata (number of zones)

$\mathrm{N}_{\mathrm{i}}$ is the size of stratum (i), which is number of household in each zone

$\mathrm{W}_{\mathrm{i}}$ is the estimated proportion of $\mathrm{N}_{\mathrm{i}}$ to $\mathrm{N}$

$P$ refers to the success probability

e stands the level of precision [1].

$\mathrm{P}$ was estimated from previous work of Kirkos sub city of Addis Abeba which is 0.37 proportion of success where used to determine the sample size. The level of precision in this study was be $4 \%$ at $5 \%$ significance level that is, $\mathrm{e}=0.04$ and $\alpha=0.05$.

Finally, by using the total number of households in towns of selected zones $(\mathrm{N}=288610)$, level of precision $(\mathrm{e}=0.034)$, the probability of success $(p=0.37)$ and the level of significance $(\alpha$ $=0.05$ ), the sample size for the study is computed to be 800 . Finally 5 percent of the sample size, which is 40 , was added to the determined sample size 800 to compensate for none response rate. Based on this relation the sample size for the $i^{\text {th }}$ stratum is obtained as

$$
\mathrm{n}_{\mathrm{i}}=\frac{\mathrm{N}_{\mathrm{i}} \mathrm{n}}{\mathrm{N}} \text {, so that } \mathrm{n}_{1}=154, \mathrm{n}_{2}=144, \mathrm{n}_{3}=192, \mathrm{n}_{4}=138, \mathrm{n}_{5}=
$$

172 Samples were considered

Table 1. Sample Sizes for the selected zones.

\begin{tabular}{llll}
\hline Name of zone & $\mathbf{N i}$ & $\mathbf{W}_{\mathbf{i}}$ & $\mathbf{n}_{\mathbf{i}}$ \\
\hline D/Birhan & 87840 & 0.005216 & 154 \\
Weldeye & 82560 & 0.005603 & 144 \\
Gondar & 118210 & 0.050123 & 192 \\
Dessei & 62450 & 0.017689 & 138 \\
D/Markos & 92644 & 0.007239 & 172 \\
Total & 800 & & \\
\hline
\end{tabular}

Method of data collection Amhara National Regional State is one of the big regions in Ethiopia. It consists of 11 zones. Since quality of life attributes in the zones are assumed to be homogeneous within a given zones and heterogeneous between different zones, stratified random sampling is applied 
to select the required sample size and to sample those respondents. A list of residential houses obtained from zones municipality was used to prepare the sampling frame of the study. Then systematic random sampling is adopted to select the required samples in each stratum. The questionnaire is adopted from previous similar works by making modification based on the research objective and study area characteristics. It was contain questions that cover both subjective and objective attributes of quality of life.

Variables in the Study In this study, several variables that are supposed to be associated with quality of life of the people have been considered. The response (dependent) variables in this study are; satisfaction level with life as whole (intuitive response), satisfaction level on housing, satisfaction level on living cost, satisfaction level on security, satisfaction level on family income, satisfaction level on access to public facilities, satisfaction level on social connectedness, satisfaction level to neighborhood sanitation, satisfaction level with quality of public service and satisfaction level on built environment. All of the above variables are categorical with four likert scales ranging from 0 (very dissatisfied) to 3 (very satisfied). The other response variable in this study is quality of life of the people in selected towns in the Zones. Quality of life is coded to take the value 0 for "low quality of life" (unsatisfied) and 1 for "high quality of life "(satisfied). As a result, it is a dichotomous variable.

The independent variables consist of demographic predictors (Age, Sex, Marital status, Religious status, Population density and Relation to head of household), Socio-economic predictors (Employment status, Monthly household income, Educational level, number of dependent children, Family size), distance to different facilities, number of rooms in a house, household tenure, home ownership, satisfaction on quality of sport and recreational place, satisfaction to access to primary school, satisfaction to health center facilities, satisfaction on police protection in the neighborhood etc. The remaining independent variables are continues type.

Method of data analysis Different statistical methods have been used for the analysis: descriptive statistics, Multivariate analysis, ordinal logistic regression and binary logistic regression are used to analyze the collected data. Descriptive analysis provided general information about the subject population. Multivariate analysis allowed for data reduction through exploratory factor analysis, ordinal logistic regression is used to assess the relationship between domains satisfaction and respective attributes of the domains and binary logistic regression use those factors which are obtained from factor analysis to see the relation they have with quality of life of the people.

\section{Multivariate statistical analysis}

Principal component analysis The general objectives of principal component analysis (PCA) are the reduction of a large number of variables whose inter relationships are complex to a much smaller set of new variables whose interrelationships are simple. Usually the covariance matrix $(\Sigma)$ is used to analyze variables with the same unit of measurement Since correlation is the covariance of standardized variable, we can use the correlation matrix $(\rho)$ to analyze the variables with different unit of measurement. PCs are particular linear combinations of the $p$ random variables $Z_{1}, Z_{2}, \ldots, Z_{p}$. Let the covariance matrix associated with the random vector $Z=\left(Z_{1}\right.$, $\left.\mathrm{Z}_{2}, \ldots, \mathrm{Z}_{\mathrm{p}}\right)^{\mathrm{t}}$ has the Eigen value-Eigen vector pairs

$\left(\lambda_{1}, \varepsilon_{1}\right),\left(\lambda_{2}, \varepsilon_{2}\right), \ldots,\left(\lambda_{\mathrm{p}}, \varepsilon_{\mathrm{p}}\right)$ where $\lambda_{1} \geq \lambda_{2} \geq \ldots \geq \lambda_{p}$, then the $i^{\text {th }}$ principal component is given by

$$
Y_{i}=e^{t} Z=e_{i 1} z_{1}+e_{i 2} \ldots+e_{i p} z_{p}, i=1,2, \ldots, p \ldots
$$

With these choices; $\operatorname{Var}\left(\mathrm{Y}_{\mathrm{i}}\right)=\mathrm{e}^{\mathrm{t}} \Sigma \mathrm{e}_{\mathrm{i}}=\lambda_{\mathrm{i}}, \mathrm{i}=1,2 \ldots \mathrm{P}$ and Cov $\left(\mathrm{Y}_{\mathrm{i},} \mathrm{Y}_{\mathrm{K}}\right)=\mathrm{e}_{\mathrm{i}}^{\mathrm{t}} \Sigma \mathrm{e}_{\mathrm{k}}=0, \mathrm{i} \neq \mathrm{k}$

As rule of thumb suggests, retaining only those components whose variance $\lambda$ are greater than unity or equivalently only those components, which individually explain at least a proportion $1 / \mathrm{p}$ of the total variance is recommended. It is a plot of $\lambda_{\mathrm{i}}$ versus $\mathrm{i}$, with Eigen values ordered from largest to smallest.

Factor Analysis Orthogonal Factor Model The factor model postulates that $\mathrm{X}$ is linearly dependent upon a few unobservable random variables $F_{1}, F_{2} . . F_{m}$, called common factors, and $\mathrm{p}$ variation $\varepsilon_{1}, \varepsilon_{2}, \ldots, \varepsilon_{\mathrm{p}}$ called errors or specific factors. The factor model is given by:

$$
\mathrm{X}_{(\mathrm{px} 1)}=\mu_{(\mathrm{px} 1)}+\mathrm{L}_{(\mathrm{pxm})} \mathrm{F}_{(\mathrm{mx} 1)}+\varepsilon_{(\mathrm{px} 1)} \ldots
$$

Where $\mathrm{L}_{(\mathrm{pxm})}=\left(\begin{array}{ccc}\mathrm{l} 11 & \cdots & \mathrm{l1m} \\ \vdots & \ddots & \vdots \\ \mathrm{lp} 1 & \cdots & \mathrm{lpm}\end{array}\right) \mathrm{F}_{(\mathrm{mx} 1)}=\left[\mathrm{F} 1, \mathrm{~F}_{2}, \ldots, \mathrm{F} \mathrm{m}\right]^{\mathrm{t}}$, $\varepsilon_{(\mathrm{px} 1}=\left[\varepsilon_{1}, \varepsilon_{2} \ldots \varepsilon_{\mathrm{p}}\right]^{\mathrm{t}}$

The coefficient $l_{\mathrm{ij}}$ is called the loading of the $\mathrm{i}^{\text {th }}$ variable on the $\mathrm{j}^{\text {th }}$ factor.

$\mathrm{i}=1,2 \ldots . \mathrm{p} ; \mathrm{j}=1,2, \ldots, \mathrm{m}$

The unobservable random vectors $F$ and $\varepsilon$ satisfy the following conditions.

- $\mathrm{F}$ and $\varepsilon$ are independent.

- $\mathrm{E}(\mathrm{F})=0, \operatorname{cov}(\mathrm{F})=\mathrm{I}_{(\mathrm{mxm})}$

- $\mathrm{E}(\varepsilon)=0, \operatorname{cov}(\varepsilon)=\Psi$, where $\Psi$ is a diagonal matrix

- $\operatorname{Cov}(\varepsilon, \mathrm{F})=0$

The Principal Component Method The variance-covariance matrix $(\Sigma)$ is symmetric and positive definite implies that all its Eigen value is positive. Thus, the spectral decomposition of covariance matrix $(\Sigma)$ having Eigen value-eigenvector pairs $\left(\lambda_{\mathrm{i}}, \mathrm{e}_{\mathrm{i}}\right)$ with $\lambda_{1}>\lambda_{2} \ldots>>0$ is given as

$$
\Sigma=\lambda_{1} \mathrm{e}_{1} \mathrm{e}_{1}{ }^{\mathrm{t}}+\lambda_{2} \mathrm{e}_{2} \mathrm{e}_{2}{ }^{\mathrm{t}}+\ldots \lambda \mathrm{pe}_{\mathrm{p}} \mathrm{e}_{\mathrm{p}}{ }^{\mathrm{t}} \ldots
$$

From above equation, we can obtain the loading;

$$
\mathrm{L}=\sqrt{\lambda_{1}} \varepsilon_{1}+\sqrt{\lambda_{2}} \mathcal{E}_{2}+\ldots \sqrt{\lambda_{p}} \mathcal{E}_{p} \ldots
$$

The Contribution to the Total Sample Variances In applying the principal component to perform factor analysis, we have use, the sample covariance matrix $\mathrm{S}$. Observe that $\mathrm{S}_{1 \lambda}+$ $\mathrm{S}_{22}+\ldots+\mathrm{S}_{\mathrm{pp}}=\operatorname{tr}(\mathrm{S})$ is trace of sample covariance matrix and $\lambda_{1}$ $+\hat{\lambda}_{2}+\ldots+\hat{\lambda}_{\mathrm{p}}=\mathrm{p}=$ trace of sample correlation matrix, where, $\hat{\lambda}_{\mathrm{i}} \mathrm{s}, \mathrm{i}=1, \ldots, \mathrm{p}$ are the estimated eigen value of $\mathrm{S}$. 
$\left[\begin{array}{l}\text { The proportion of total sample } \\ \text { variance due to } \mathrm{j}^{\text {th }} \text { factor }\end{array}\right]=\frac{\hat{\lambda}_{j}}{\operatorname{tr}(s)}$, for factor analysis of sample covariance

$\left[\begin{array}{l}\text { The proportion of total sample } \\ \text { variance due to } \mathrm{j}^{\text {th }} \text { factor }\end{array}\right]=\frac{\hat{\lambda}_{j}}{p}$, for factor analysis of correlation

Factor Rotation Method Factor rotation is an orthogonal transformation of the factor loadings, as well as the implied orthogonal transformation of the factors; the estimated covariance (correlations) matrix remains unchanged since

$$
\hat{L} \hat{L}^{T}+\hat{\Psi}=\hat{L} T T^{T} \hat{L}^{T}+\hat{\Psi}=\hat{L}^{*} \hat{L}^{* T}+\hat{\Psi}
$$

\section{Results and Discusions}

Individuals and household characteristics A sample of 809 respondents from five Zones of Amhara national regional state (ANRS) is collected to achieve the main objective of this study A four point likert scale ranged from 1 to 4 is used to measure individual's responce on their quality of life (QOL), domain satisfaction and its attributies; $1,2,3 \& 4$ start to very dissatisfied, dissatisfied, satisfied and highly satisfied for the subjective and objective quality of life respectively.

Table 1 shows that there are more male respondents $(63.7 \%)$ than female respondents $(36.3 \%)$. This is compared to the result of Elsa's paper (Elsa, 2009) in which $56.7 \%$ were males and $43.3 \%$ were females. And this can further be compared with the report of Ethiopia's plan for accelareted and suistained developement to end poverty. The report stated that in urban Ethiopia there are more male headedhousehold (61\%) than female headed households (39\%). The respondents age ranges from 18 to 75 with mean 33.99 and standard deviation 11.23. Interms of marital status, the majority of the head of the household (52.9\%) are married. Educational charactersitics of the heads of the households shows that the majority( $93.3 \%$ ) are litrate while only $6.7 \%$ are ilitrate. It was observed that $34.1 \%$ attained education up to secondary level.

Table 1. Individual Charactersitics.

\begin{tabular}{llll}
\hline Description & Category & Frequancy & \% \\
\hline \multirow{2}{*}{ Sex } & Male & 515 & $63.7 \%$ \\
& Female & 294 & $36.3 \%$ \\
& Single & 322 & $39.8 \%$ \\
Marital status & Married & 428 & $52.9 \%$ \\
& Widowed & 30 & $3.7 \%$ \\
& Divorced & 29 & $3.6 \%$ \\
Employment & Non employed & 195 & $24.1 \%$ \\
status & Governmental & 317 & $39.2 \%$ \\
& Non government & 112 & $13.8 \%$ \\
& Private company & 185 & $22.9 \%$ \\
Educational & Non - educated & 54 & $6.7 \%$ \\
level & Secondary school & 276 & $34.1 \%$ \\
& Certificate/diploma & 241 & $29.8 \%$ \\
& Degree & 196 & $24.1 \%$ \\
\hline
\end{tabular}

Table 2 below shows the household characteristics i.e. household size, number of dependent children and family income. In terms of household size, out of the total respondents, only $27.5 \%$ live in household of size less than 3 people per house. Almost half of the respondent's i.e. $49.3 \%$ lives in households between 3-5 persons. In terms of dependent children, $35.4 \%$ of the respondents have no dependent children. Almost half (48.3\%) of the respondents have 2 and more dependent children. In terms of monthly income, $19.4 \%$ of the respondent's family earns less than 500 Ethiopian birr while $10.9 \%$ will get monthly income more than 4501 and private home owners and rent from private respondents are almost equal $37.8 \%$ and $38.2 \%$ respectively.

Table 2. Household Charactersitics.

\begin{tabular}{llll}
\hline Description & Categories & Frequency & \% \\
\hline \multirow{3}{*}{ Household size } & $1-2$ persons & 222 & $27.5 \%$ \\
& 3-5 persons & 399 & $49.3 \%$ \\
& 6-9 persons & 158 & $19.5 \%$ \\
& 10 and more & 30 & $3.7 \%$ \\
Number of & no dependent & 286 & $35.4 \%$ \\
dependent & 1 dependent & 132 & $16.3 \%$ \\
persons & 2 dependent & 154 & $19.0 \%$ \\
& $3-5$ dependent & 206 & $25.5 \%$ \\
& 6 \& more & 31 & $3.8 \%$ \\
& less than 500 & 157 & $19.4 \%$ \\
Family income & $500-1500$ & 250 & $30.9 \%$ \\
& $1501-2500$ & 171 & $21.1 \%$ \\
& $2501-3500$ & 94 & $11.6 \%$ \\
& $3501-4500$ & 49 & $6.1 \%$ \\
& 4501 and more & 88 & $10.9 \%$ \\
& Private & 306 & $37.8 \%$ \\
Housing tenure & Housing agency & 72 & $8.9 \%$ \\
& Kebele & 122 & $15.1 \%$ \\
& Rent & 309 & $38.2 \%$ \\
\hline
\end{tabular}

Summary of intuitive and rational QOL The subjective quality of life is measured by either intiutive response or rational response. The intiutive subjective quality of life in the five city of the region is meaured by asking respondents what they feel about their life as whole during the time of the household survey i.e 2011 and two years before the time of the house hold survey. But the rational subjective quality of life is the integreted satisfaction of individuals with domains of life and is computed after individuls were asked about their satisfaction with specific domains of life. The next table shows the percentage of respondents in Amhara region that are categorized in each level of quality of life based on their intiutive response. When respondents were asked about their life, about $27.8 \%$ express their dissatisfaction while only $40.2 \%$ of respondents are satisfied with their life.The mode for the subjective quality of life is 3 which refers as satisfied.

Table 3. Percentage of Intiutive QOL score in 2013/2014 (Amhara region, 2013/2014).

\begin{tabular}{llllll}
\hline \multirow{2}{*}{$\begin{array}{l}\text { Level of } \\
\text { QOL }\end{array}$} & \multicolumn{2}{l}{ Quality of Life } & & & \\
\cline { 2 - 6 } & frequency & $\%$ & Commulative & $\begin{array}{l}\text { Overall Amhara } \\
\text { region }\end{array}$ & \\
\hline $\begin{array}{l}\text { Very } \\
\text { dissatisfied }\end{array}$ & 204 & 25.2 & 25.2 & Mean(likert) & 2.29 \\
$\begin{array}{l}\text { Dissatisfied } \\
\text { Satisfied }\end{array}$ & 225 & 27.8 & 53.0 & & \\
$\begin{array}{l}\text { Highly } \\
\text { satisfied }\end{array}$ & 525 & 40.2 & 93.2 & Mode & 3 \\
& & 6.8 & 100.0 & Standard & 0.919 \\
\hline
\end{tabular}




\section{deviation}

The rational quality of life is categorical with two levels. Table 4 indicates the percentage of respondents in Amhara region that are categorized in the two levels were asked their feeling about their life in general, above half percent of them $53 \%$ said they were unsatisfied with their life while only $47 \%$ of the respondents were satisfied with their life as whole).This result disagrees with the finding by [13] and [9] that reported higher percentage of respondents that are satisfied in terms of rational response than intuitive response for the selected settlements in Krikos sub city of Addis Ababa and Singapore respectively. This is due to respondents were feeling dissatisfied or worst with cost of living and rise of price of items in recent years. And irrational response and unintuitive response for selected zones towns.

Table 4. Percentage of overall Quality of Life.

\begin{tabular}{lll}
\hline Levels & Frequency & \% \\
\hline Unsatisfied & 429 & 53 \\
Satisfied & 380 & 47 \\
Total & 809 & 100 \\
\hline
\end{tabular}

Summary of satisfaction with domains of life Quality of life is often determined by satisfaction with several domains of life. The idea that quality of life could be conceptualized as a composite of more specific domain measures has been pursued by many researchers. Thus, the domain of life identified for this study are housing, built enviromnent, neighborhood safety, neighborhood sanitation, quality of puplic servise, access to puplic servises, social connectedness, family income and cost of living. Percentage of respondents in each level of domain satisfaction, the mean and standard deviation of each domain satifaction are shown in Table 6.

More than half of the respondents felt dissatiesfied or worst in three of the nine domains. These domains are;neighborhood sanitation, quality of puplic servise and family income. Only $5.8 \%$ of the respondents are satisfied with cost of living. The most favorable evaluated domain interms of mean score is social connectedness, neighborhood safety, housing and the least favorable evaluated domain interms of mean score is cost of living. Housing, built enviromnent, acces to puplic servise and social connectedness have the same modal level (satisfied). In the same way neighborhood sanitation, neghborhood safety, quality of puplic servise and family income have also the same modal category(dissatiesfied) while the modal category for satisfaction with cost of living is highly dissatisfied.

Table 5. Descriptive Statistics for Domain Satisfaction at Amhara region, 2013/2014).

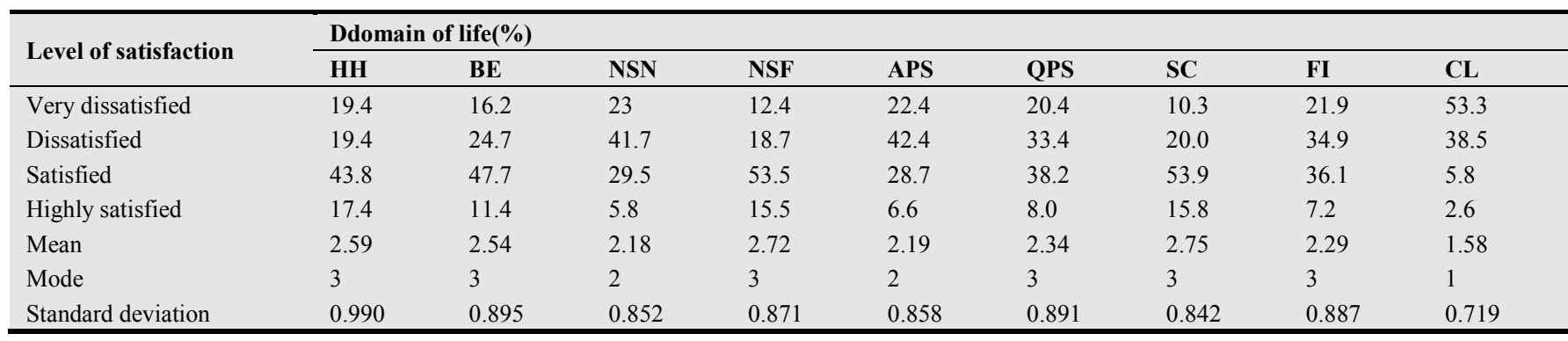

$\mathrm{HH}=$ housing, $\mathrm{BE}=$ built enviromnent, $\mathrm{NSN}=$ neighborhood sanitation, $\mathrm{NSF}=$ neighborhood safety, APS=acces to puplic servise, $\mathrm{QPS}=\mathrm{quality}$ of puplic servise, $\mathrm{SC}=$ social connectedness, $\mathrm{FI}=$ family income, $\mathrm{CL}=$ cost of living

Table 6. Mean Satisfaction Score of Domains at at Amhara region, 2013/2014.

\begin{tabular}{|c|c|c|c|c|c|c|c|c|c|}
\hline \multirow{2}{*}{ Zone city } & \multicolumn{9}{|c|}{ Domains of life (mean satisfaction score) } \\
\hline & HН & BE & NSN & NSF & APS & QPS & SC & FI & CL \\
\hline DebreBirhan & 1.34 & 1.38 & 1.65 & 1.36 & 1.76 & 1.23 & 1.80 & 1.34 & 0.45 \\
\hline Debre Markos & 1.45 & 1.66 & 1.56 & 1.27 & 1. 28 & 1.44 & 1. 58 & 1.21 & 0.49 \\
\hline Gondar & 1.70 & 1.47 & 1.54 & 1.13 & 1.39 & 1.25 & 1.64 & 1.93 & 0.67 \\
\hline Woldia & 1.65 & 1.91 & 1.22 & 1. 29 & 1.54 & 1.15 & 1.54 & 1.32 & 0.51 \\
\hline Dessie & 1.25 & 1.84 & 1.34 & 1.23 & 1.80 & 1.23 & 1.82 & 1.38 & 0.59 \\
\hline
\end{tabular}

$\mathrm{HH}=$ housing, $\mathrm{BE}=$ built enviromnent, $\mathrm{NSN}=$ neighborhood sanitation, $\mathrm{NSF}=$ neighborhood safety, APS=acces to puplic servise, $\mathrm{QPS}=$ quality of puplic servise, $\mathrm{SC}=$ social connectedness, $\mathrm{FI}=$ family income, $\mathrm{CL}=$ cost of living

Table 6 shows domain satisfaction at the sub-zone level. As shown in the Table, the mean of the satisfaction score varies from 0.49 to 1.93 . The domain that scores the least is cost of living in Debre Birhan town while the highest is family incomein Gondar town. Compared with respondents in other town, Woldia express highest satisfaction in built enviromnent and also compared with respondents in other town, Debre Markos express highest satisfaction in quality of puplic servise. Out of the nine domains, the respondents from Gondar town express least satisfaction in; neighborhood safety. In all towns, respondents express dissatisfaction or worst feeling for cost of living.

Summaries of Satisfaction level of attributes Respondents satisfaction level with each attributes in terms of percentage are shown in the table below. Respondents offered a four point likert scale ranging from 1 which represents "very dissatisfied" 
to 4 which represent "very satisfied" to measure their level of satisfaction for each attribute. Only $2.7 \%$ (minimum in the category of dissatisfaction) of the respondents feel worst (very dissatisfied) while $52 \%$ ( maximum in the category of satisfaction) of the respondents are satisfied on "weather condition of Amhara region". High dissatisfaction is observed under the variable "family income".

Table 7. Percentage of Respondents Satisfaction Level for Each Attributes in the region.

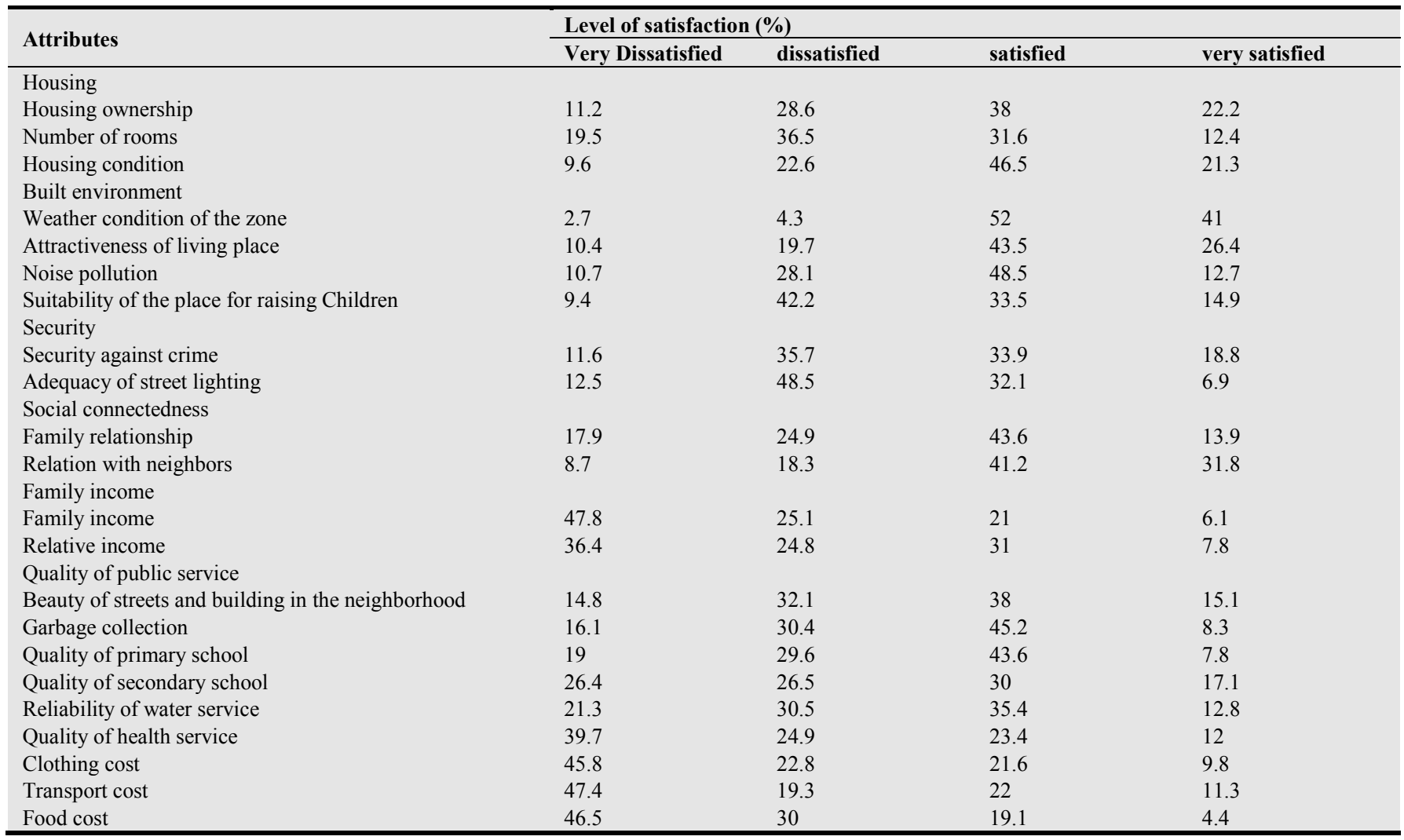

Ordinal logistic regression results In this study ordinal logistic regression is used to analyze the relationship between domains satisfaction and respective attributes which are measured by a four point likert scale. For the study 9 domains were selected and 9 models were developed to assess the relation between domain satisfaction and the respective attributes.

The major decisions involved in constructing the ordinal regression models were deciding what explanatory variables to include in the model equation and choosing link functions that would be the best fit to the data set. Two commonly used link functions, namely; logit link and clog log link, and then the logit link function might be appropriate, were chosen to build the ordinal regression models. If the frequency distribution of the ordered categorical outcome shows that a large percent of respondents are in higher categories such as very satisfied and satisfied ratings, then the clog log link function might be suitable. In fact, there is no clear-cut choice of link function. If one link function does provide a good fit to the data, then the other link function might be a viable alternative. In this study, the model assumption of parallel lines across the corresponding response categories in the link functions was carefully examined to determine the model adequacy. Because the link functions were used to form the ordinal regression models under a strong assumption of parallel lines, any departures from this assumption might result in the incorrect analysis and conclusion [20]. SPSS version 16 is used to perform the ordinal logistic regression.

Table 8. The Hosmer and Lemeshow Test Output for 27 Models Amhara region, 2013/2014.

\begin{tabular}{|c|c|c|c|}
\hline Dimension & Dependent variable & Chi-square & Sig. \\
\hline \multirow{3}{*}{ Housing } & Housing(dissatisfied) & 5.210 & .854 \\
\hline & housing (satisfied) & 2.402 & .564 \\
\hline & Housing (very satisfied) & 3. 612 & 0.695 \\
\hline \multirow{3}{*}{ Built environment } & Built environment(dissatisfied) & 23.241 & 0.018 \\
\hline & Built environment(satisfied) & 32.452 & 0.000 \\
\hline & Built environment(satisfied) & 12.711 & 0.029 \\
\hline \multirow{2}{*}{ Social connectedness } & Social connectedness (dissatisfied) & 4. 010 & 0.676 \\
\hline & Social connectedness (very satisfied) & 8. 918 & 0.237 \\
\hline Neighborhood safety & Neighborhood safety (dissatisfied) & 4.827 & 0.436 \\
\hline
\end{tabular}




\begin{tabular}{llll}
\hline Dimension & Dependent variable & Chi-square & Sig. \\
\hline & Neighborhood safety (satisfied) & 4.687 & 0.584 \\
& Neighborhood safety (very satisfied) & 3.769 & 0.937 \\
& Access to public service(dissatisfied) & 9.859 & 0.031 \\
Access to public service & Access to public service (satisfied) & 45.547 & 17.873 \\
& Access to public service very satisfied) & 2.612 & 0.027 \\
& Quality of public service(dissatisfied) & 11.589 & 0.007 \\
Quality of public service & Quality of public service(satisfied) & 9.536 & 0.010 \\
& Quality of public service (very satisfied) & 11.660 & 0.022 \\
Neighborhood sanitation & Neighborhood sanitation (dissatisfied) & 3.506 & 0.596 \\
& Neighborhood sanitation(satisfied) & 2.119 & 0.928 \\
Cost of living & Neighborhood sanitation(very satisfied) & 3.606 & 0.219 \\
& Cost of living (dissatisfied) & 7.309 & 0.092 \\
Family income & Cost of living (satisfied) & 8.047 & 0.473 \\
& Cost of living(very satisfied) & 12.648 & 0.753 \\
& Family income (dissatisfied) & 14.654 & 0.214 \\
\hline
\end{tabular}

Before the ordinal logistic regression model is examined, it is mandatory to run binary logistic regression for the dichotomized response and assess the goodness of fit. Since each ordered response variable is with 4 levels, we do have three dichotomized variables for each response variable and a total of 27 dichotomized variables. The Hosmer and Lemeshow test results are given in Table 8 for different combinations. The Table shows a p-value less than 0.05 for three variables is significance in the categories. Thus Hosmer and Lemeshow test allows us to apply the ordinal logistic regression for six ordinal response variables except built environment, access to public service, quality of public service.

Model Fitting Information Following the result of the goodness of fit test, ordinal logistic regression for built environment, access to public service and quality of public service is disregarded and the model fitting information is given for the six models in Table 9.The model for cost of living is significant (chi-square 327.437, $\mathrm{df}=4, \mathrm{p}<.05$ ) at $5 \%$ of significance whenever all the three predictors are considered together. All others are the same way to express at $5 \%$ level of significance.

Pseudo $R$ square Table 10 shows the values of the three pseudo R square measures; Cox and Snell, Nagelkerke and McFadden for each eight proportional odds model. The results support the conclusion that the model fit the data well for each model.

Table 9. The Model Fitting Information Amhara region, 2013/2014.

\begin{tabular}{|c|c|c|c|c|c|}
\hline Dependent variable & Model & -2 Log Likelihood & Chi-Square & Df & Sig. \\
\hline & Intercept Only & 628.288 & & & \\
\hline Housing & Final & 424.105 & 395.280 & 3 & .000 \\
\hline Social connectedness & $\begin{array}{l}\text { Intercept Only } \\
\text { Final }\end{array}$ & $\begin{array}{l}810.403 \\
148.120\end{array}$ & 434.286 & 2 & .000 \\
\hline \multirow[t]{2}{*}{ Neighborhood sanitation } & Intercept Only & 505.474 & & & \\
\hline & Final & 238.313 & 267.341 & 3 & .000 \\
\hline Family income & Intercept Only & 448.378 & & & \\
\hline \multirow[t]{2}{*}{ Neighborhood safety } & Intercept Only & 629.869 & & & \\
\hline & Final & 497.746 & 183.321 & 3 & .000 \\
\hline \multirow[t]{2}{*}{ Cost of living } & Intercept Only & 680.860 & & & \\
\hline & Final & 327.437 & 383.490 & 4 & .000 \\
\hline
\end{tabular}

Table 10. Pseudo $R$ Squares Values for each 6 Models Amhara region, 2013/2014.

\begin{tabular}{lll}
\hline Dependent variable & Measures square & Value \\
\hline \multirow{3}{*}{ Housing } & Cox and Snell & 0.584 \\
& Nagelkerke & 0.724 \\
& McFadden & 0.358 \\
Social connectedness & Cox and Snell & 0.595 \\
& Nagelkerke & 0.607 \\
& McFadden & 0.332 \\
Neighborhood sanitation & Cox and Snell & 0.379 \\
& Nagelkerke & 0.413 \\
& McFadden & 0.169 \\
Family income & Cox and Snell & 0.289 \\
\hline
\end{tabular}

\begin{tabular}{lll}
\hline Dependent variable & Measures square & Value \\
\hline \multirow{3}{*}{ Neighborhood safety } & Cox and Snell & 0.375 \\
& Nagelkerke & 0.439 \\
& McFadden & 0.184 \\
Cost of living & Cox and Snell & 0.521 \\
& Nagelkerke & 0.726 \\
\hline
\end{tabular}

Link function: Logit.

Table 11 shows that level of housing ownership, housing condition and number of rooms are statistically significant predictors of satisfaction on housing. So for level of housing ownership, It can be said that for a one unit increase in level of satisfaction on housing ownership (i.e., going from 0 to 1 ), 
there will be a 0.289 increase in the ordered log odds of being in a higher level of housing satisfaction, given all of the other variables in the model are held constant. For housing condition, we would say that for a one unit increase with housing condition satisfaction(i.e. going from 0 to 1 ), we would expect a 0.341 increase in the log odds of being in a higher level of housing satisfaction, given that all of the other variables in the model are held constant. For number of rooms, a one unit increase on number of room's satisfaction will produce 2.187 increases in the log odds of being in higher level of satisfaction on housing. All of the predictors are statistically significant in predicting Social connectedness satisfaction. Both of the predictors: family relationship and relation with neighbors are significant predictors of satisfaction on social life. A person who is satisfied with his/ her family relationship is expected to be better satisfied with his/her social life. But satisfaction on relation with neighbors has least impact on satisfaction with social connectedness. Beauty of street and building in the neighborhood, weather condition of the city and efficiency in garbage collection are all significant predictors of neighborhood sanitation. The beauties of street and building in the neighborhood have strong impact on satisfaction with neighborhood sanitation. Others are express similar manner.
The parameter estimate table also shows that satisfaction with absolute income is positively and significantly related with income $(\beta=.896$ and $\mathrm{P}<.05)$. Satisfaction on relative income is also positively and significantly related with income $(\beta=1.332$ and $\mathrm{P}<.05)$. Relative income is found to be the most important predictor of income than absolute monthly income.

Crime in the neighborhood is the only covariate (predictor) which is statistically significant predictor of satisfaction on neighborhood safety. The positive sign of the coefficient indicates; as crime in the neighborhood getting less, household's satisfaction on neighborhood safety increases. Since the P-value associated with the variables "adequacy of street lighting" and "police protection on the neighborhood is small" is greater than. 05 , the two variables are not significant predictors of satisfaction on neighborhood safety.

Clothing cost and food item costs are found to be statistically significant as both have associated P-values less than. 05. Both predictors have a coefficient with positive sign to indicate as the people are able to buy clothes, food and related items without any difficulties; they thought that cost of living is not high. The associated coefficient for transport cost and public service cost is small and their P-value greater than 0.05 . So the two variables are not significant predictors of satisfaction with cost of living.

Table 11. Parameter Estimates Amhara region, 2013/2014.

\begin{tabular}{|c|c|c|c|c|c|c|c|}
\hline \multirow{2}{*}{ Dependent variables } & & & \multirow{2}{*}{ Estimate } & \multirow{2}{*}{ Wald } & \multirow{2}{*}{ Sig. } & \multicolumn{2}{|c|}{ 95\% Confidence Interval } \\
\hline & & & & & & Lower bound & Upper bound \\
\hline \multirow{7}{*}{ Housing } & \multirow{3}{*}{ Threshold } & {$[\mathrm{slh}=.00]$} & 1.507 & 28.152 & .001 & 0.644 & 1.970 \\
\hline & & {$[\mathrm{slh}=1.00]$} & 4. 372 & 230.185 & .016 & 3. 129 & 5.425 \\
\hline & & {$[\mathrm{slh}=2.00]$} & 5.830 & 312.980 & .020 & 6.906 & 7.150 \\
\hline & \multirow{3}{*}{ Location } & Slho & 0.289 & 5. 749 & .000 & 0.057 & 0.542 \\
\hline & & $\mathrm{Hc}$ & 0.341 & 6.917 & .002 & 0.195 & 0.740 \\
\hline & & Sltnr & 2. 187 & 118. 203 & .010 & 1.255 & 4.180 \\
\hline & \multirow{3}{*}{ Threshold } & {$[\mathrm{slsc}=0.00]$} & 1.061 & 22.622 & .003 & .624 & 1.498 \\
\hline \multirow[t]{2}{*}{ Social connectedness } & & {$[\mathrm{slsc}=1.00]$} & 4.269 & 222.769 & .000 & 3.708 & 4.829 \\
\hline & & {$[\mathrm{slsc}=2.00]$} & 7.534 & 379.228 & .010 & 6.776 & 8.293 \\
\hline \multirow{6}{*}{ Neighborhood sanitation } & \multirow{2}{*}{ Location } & Frship & 2.487 & 226.317 & .000 & 2.163 & 2.811 \\
\hline & & Rwn & 0.379 & 9.795 & .000 & 0.141 & 0.616 \\
\hline & \multirow{3}{*}{ Threshold } & {$[\operatorname{sitns}=.00]$} & 3.621 & 21.294 & .001 & 2. 433 & 4.122 \\
\hline & & {$[$ sltns $=1.00]$} & 5.652 & 73.918 & .000 & 6.477 & 9.711 \\
\hline & & {$[$ sltns $=2.00]$} & 2.967 & 112.421 & .000 & 3.623 & 5. 370 \\
\hline & \multirow{3}{*}{ Location } & Bsbn & 4.126 & 169.616 & .000 & 2. 845 & 6.761 \\
\hline \multirow{5}{*}{ Cost of living } & & Wch & 1.863 & 19.135 & .002 & 1.815 & 3. 126 \\
\hline & & Gc & 0.963 & 5.455 & .024 & 1.071 & 2.520 \\
\hline & \multirow{3}{*}{ Threshold } & {$[\mathrm{scl}=.00]$} & 2.337 & 121.474 & .000 & 1.035 & 3. 268 \\
\hline & & {$[\mathrm{scl}=1.00]$} & 1. 384 & 99.188 & .000 & 1.768 & 3. 806 \\
\hline & & {$[\mathrm{scl}=2.00]$} & 5.107 & 211.138 & .000 & 4.721 & 8.233 \\
\hline \multirow{8}{*}{ Neighborhood safety } & \multirow[t]{5}{*}{ Location } & $\mathrm{Cc}$ & 3. 752 & 173.026 & .001 & 4.035 & 5.211 \\
\hline & & $\mathrm{Tc}$ & -0.037 & 0.112 & .536 & -0.942 & 0.4260 \\
\hline & & $\mathrm{Fc}$ & 0.630 & 14.149 & .000 & 0.263 & 1. 460 \\
\hline & & Psc & 0.307 & 9.525 & .212 & -0.157 & 0.9810 \\
\hline & & {$[\operatorname{sins}=.00]$} & 1.121 & 6.321 & .001 & 0.645 & 2. 124 \\
\hline & \multirow[t]{2}{*}{ Threshold } & {$[\operatorname{sln} s=1.00]$} & 3.127 & 178.238 & .000 & 2. 921 & 5.423 \\
\hline & & {$[\mathrm{s} \ln \mathrm{s}=2.00]$} & 1.927 & 36.815 & .000 & 1.342 & 2.480 \\
\hline & \multirow{3}{*}{ Location } & asl & 1. 854 & 182.793 & .000 & 1.431 & 2.427 \\
\hline \multirow{7}{*}{ Family income } & & $\operatorname{ctn}$ & -0.014 & 0.017 & .753 & -0.152 & 0.197 \\
\hline & & ppn & -0.143 & 1.295 & .126 & -0.364 & 0.278 \\
\hline & \multirow{3}{*}{ Threshold } & {$[\mathrm{slf}=.00]$} & 0.275 & 13.115 & .001 & 0.140 & 1. 213 \\
\hline & & {$[\mathrm{slf}=1.00]$} & 2.600 & 73.055 & .000 & 2.104 & 3. 503 \\
\hline & & {$[\mathrm{slf}=2.00]$} & 6.753 & 287.012 & .000 & 5.973 & 7. 597 \\
\hline & \multirow{2}{*}{ Location } & rrincome & 1.042 & 43.322 & .000 & 0.940 & 1.544 \\
\hline & & fic & 0.765 & 31.513 & .000 & 0.824 & 1. 274 \\
\hline
\end{tabular}


Link function: Logit.

Table 12. Result of Parallel Lines Test Assumption Amhara region, 2013/2014.

\begin{tabular}{|c|c|c|c|c|c|}
\hline Model & Hypothesis & -2 Log Likelihood & Chi-Square & df & Sig.(p-value) \\
\hline \multirow{2}{*}{ Housing } & Null Hypothesis & 324.120 & & & \\
\hline & General & 316.239 & 5.232 & 6 & .643 \\
\hline Social connectedness & $\begin{array}{l}\text { Null Hypothesis } \\
\text { General }\end{array}$ & $\begin{array}{l}112.320 \\
105.543\end{array}$ & 3.645 & 4 & 452 \\
\hline \multirow{2}{*}{ Neighborhood sanitation } & Null Hypothesis & 232.313 & \multirow{3}{*}{ 4. 926} & \multirow{3}{*}{6} & \multirow{3}{*}{.253} \\
\hline & General & 222.414 & & & \\
\hline Family & Null Hypothesis & 314.221 & & & \\
\hline income & General & 301.539 & 5.013 & 4 & 420 \\
\hline \multirow{2}{*}{ Neighborhood safety } & Null Hypothesis & 456.267 & \multirow{3}{*}{8.195} & \multirow{3}{*}{6} & \multirow{3}{*}{.516} \\
\hline & General & 442.128 & & & \\
\hline \multirow{2}{*}{ Cost of living } & Null Hypothesis & 247.267 & & & \\
\hline & General & 238.730 & 13.347 & 8 & .256 \\
\hline
\end{tabular}

The null hypothesis states that the location parameters (slope coefficients) are the same across response categories. Link function: Logit

Factor analysis for the reduction of subjective attributes Multivariate analysis in the form of factor was conducted on all subjective QOL attributes of each domain. This had three objectives. Firstly, it helps to derive a limited number of manageable and meaningful constructs with a minimum loss of information, secondly to identify whether the classification of attributes to the respective domain is correct or some modification is required for future works. It also helps to identify additional domains of quality of life of the subjective part and to asses if there is interaction across domains.

Before factor analysis is conducted, the reliabilities of the variables (data) were checked against the recommended standards (Cronbach $\alpha \geq 0.70$ ) mainly to ensure that they are reliable indicators of the constructs. An exploratory factor analysis using principal components has been applied using 20 subjective attributes that were obtained from the household survey. Orthogonal factors were obtained using varimax rotation. Only those factors with an Eigen value greater than 0.9 and high Cronbach $\alpha$ coefficient are considered. A factor loading of 0.45 has been used to screen out variables that are weak indicator components of subjective attributes. The data set was checked and it met the criteria for Bartlett's Test of Sphericity. Since the P value (.000) is less than the test of significance $(\alpha=0.05)$ and the Kaiser-Meyer-Olkin (KMO) measure of sampling adequacy is 0.912 which is greater than 0.5 (greater than 0.05 ) indicating that there are probably significant relationships among attributes of the subjective QOL and hence data are suitable for factor analysis (Table 13). [13] recommended a loading of greater than or equal to 0.7 indicates an excellent strength of relation between the factor and the variables and a loading less than or equal to 0.32 indicates poor relationship.

In varimax rotation factor solution for the original 20 attributes, $71.54 \%$ of the total variance was explained by the first 6 factors with eigen values greater than 0.9. After rotation, the first factor accounted for $32.82 \%$ of the variance, the second factor accounted for $19.52 \%$, the third factor accounted for $11.05 \%$, the fourth factor accounted for $9.32 \%$, and the fifth and the sixth factor accounted for $7.12 \%$, and $6.71 \%$ respectively.

Table 13. KMO and Bartlett's Test for the Reduction of Subjective Attributes.

\begin{tabular}{lll}
\hline \multicolumn{2}{l}{ Kaiser-Meyer-Olkin Measure of Sampling Adequacy } & $\mathbf{0 . 9 1 2}$ \\
\hline \multirow{3}{*}{ Bartlett's Test of Sphericity } & Approx. Chi-Square & 3892.72 \\
& & \\
& Degrees of freedom & 205 \\
& Sig. & .000 \\
\hline
\end{tabular}

Table 14. Factor Loading Matrix for the Reduction of Subjective Attributes.

\begin{tabular}{|c|c|c|c|c|c|c|}
\hline \multirow{2}{*}{ Subjective attributes } & \multicolumn{6}{|l|}{ Factors } \\
\hline & 1 & 2 & 3 & 4 & 5 & 6 \\
\hline the beauty of streets and building in the neighborhood & 0.957 & & & & & \\
\hline attractiveness of the living place & 0.875 & & & & & \\
\hline garbage collection & 0.858 & & & & & \\
\hline weather condition of the city & -0.789 & & & & & \\
\hline neighborhood is congested & 0.554 & & & & & \\
\hline clothing cost & & 0.829 & & & & \\
\hline food cost & & 0.741 & & & & \\
\hline family income & & 0.662 & & & & \\
\hline relative income & & 0.502 & & & & \\
\hline reliability of water service & & & 0.912 & & & \\
\hline quality of health facility & & & 0.842 & & & \\
\hline quality of primary school & & & 0.812 & & & \\
\hline satisfaction level of housing ownership & & & & 0.811 & & \\
\hline satisfaction level on the number of rooms & the house & & & 0.757 & & \\
\hline suitability of the place for raising children & & & & & 0.862 & \\
\hline
\end{tabular}




\begin{tabular}{|c|c|c|c|c|c|c|}
\hline \multirow{2}{*}{ Subjective attributes } & \multicolumn{6}{|c|}{ Factors } \\
\hline & 1 & 2 & 3 & 4 & 5 & 6 \\
\hline crime in the neighborhood & & & & & 0.811 & \\
\hline noise pollution & & & & & 0.672 & \\
\hline relation with neighbors & & & & & & 0.819 \\
\hline family relationship & & & & & & 0.802 \\
\hline eigen value & 5.85 & 2.93 & 1.85 & 1.72 & 1.44 & 0.965 \\
\hline percentage of variance explained & 32.82 & 19.52 & 11.05 & 7.32 & 7.12 & 6.71 \\
\hline total variation explained & 71.54 & & & & & \\
\hline
\end{tabular}

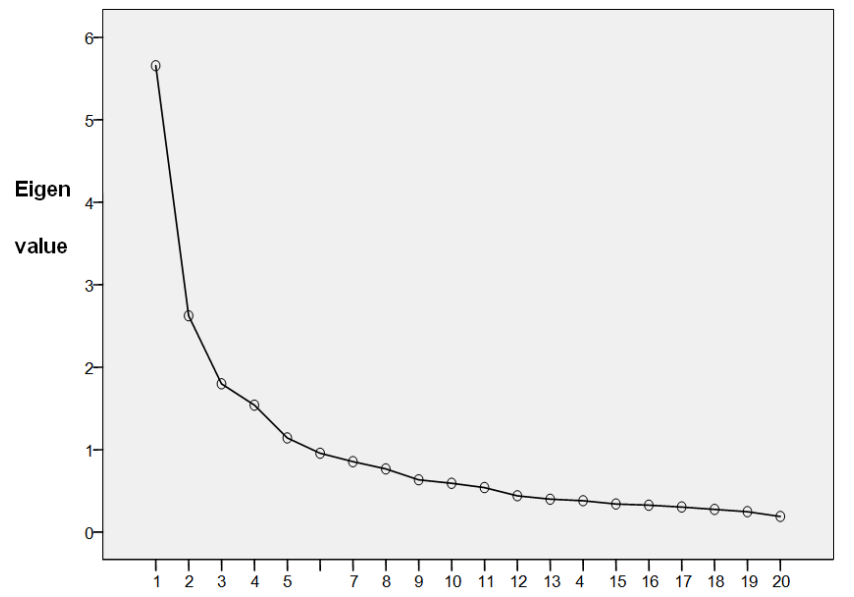

Fig. 1. Scree Plots for the reduction of Subjective Attributes.

Both the scree plot and the Eigen values support the conclusion that these 20 attributes can be reduced to six components. The scree plot flattens out after the sixth component (see Figure 1).

A comparison between the variables (attributes) of the six factors and the attributes of domains of life for the subjective part of the household survey and the physical meaning for the first up to the six dimensions of subjective QOL loading factors are: neighborhood sanitation, economic, quality of public services, housing, environmental and social relation respectively.

Binary logistic regression of overall relation between QOL and SDS Binary logistic regression is applied to assess the relationship between overall quality of life which is dichotomized response variable (unsatisfied /satisfied) and domain scores which are obtained from the factor analysis of subjective attributes. SPSS version 16 is used to perform binary logistic regression by making the unsatisfied level as reference category. Before applying the final multiple logistic regression models with six covariates for the intended purpose it has to be assessed and diagnosed for all possible model inadequacies.

Assessing Model Fit After the logistic model is formed using the selected predictor variables; the first step is to assess the overall fit of the model to the data. Table 15 shows the non-significance of the chi-square value, there is no evidence to accept the alternative hypothesis that there is no difference between the observed and expected frequencies which indicates that the model adequately fits the data.

Table 15. Hosmer and Lemeshow Test for the Relationship between Overall Quality of life and Subjective Domains Score.

\begin{tabular}{llll}
\hline Step & Chi-square & Df & Sig. \\
\hline 1 & 11.810 & 8 & .826 \\
\hline
\end{tabular}

Another way of assessing the goodness of the fitted model is to see how well the model classifies the observed data. Table 16 reveals that, overall, $82.16 \%$ of the participants were predicted correctly. The independent/covariate variables were better at helping us predict who would not be satisfied $(76.19 \%$ correct) than at who would be satisfied $(71.1 \%$ correct $)$.

Table 16. Classification Table for the relationship between Overall Quality of life and Subjective domains score.

\begin{tabular}{lllll}
\hline & & \multicolumn{2}{l}{ Predicted } \\
\cline { 3 - 5 } Observed & & \multicolumn{2}{c}{ Overall Quality of Life } & $\begin{array}{l}\text { Percentage } \\
\text { Correct }\end{array}$ \\
\cline { 3 - 5 } & & Unsatisfied & Satisfied & \\
\hline $\begin{array}{l}\text { Quality of Life } \\
\text { Score }\end{array}$ & Unsatisfied & 336 & 93 & 76.19 \\
& Satisfied & 69 & 311 & 71.1 \\
Overall Percentage & & & & 82.16 \\
\hline
\end{tabular}

Table 17. Model Summary for the Relationship between overall quality of life and subjective domains score.

\begin{tabular}{llll}
\hline Step & $\mathbf{- 2}$ Log likelihood & $\begin{array}{l}\text { Cox \& Snell R } \\
\text { Square }\end{array}$ & $\begin{array}{l}\text { Nagelkerke R } \\
\text { Square }\end{array}$ \\
\hline 1 & $483.36(\mathrm{a})$ & .428 & .554 \\
\hline
\end{tabular}

Table 17 shows that $55.4 \%$ of the variance in whether or not respondents satisfied with their life as whole can be predicted from a linear combination of the six independent variables. The multiple logistic regression coefficients can be estimated using the maximum likelihood estimation method implemented in the SPSS package. The results are displayed in Table 18.

Table 18. Variables in the Equation for the Relationship between Overall Quality of life and Subjective Domains Score.

\begin{tabular}{|c|c|c|c|c|c|c|c|c|}
\hline & \multirow{2}{*}{$\boldsymbol{\beta}$} & \multirow{2}{*}{ S.E. } & \multirow{2}{*}{ Wald } & \multirow{2}{*}{ Df } & \multirow{2}{*}{ Sig. } & \multirow{2}{*}{$\operatorname{Exp}(\beta)$} & \multicolumn{2}{|c|}{ 95.0\% C.I. for $\operatorname{Exp}(\beta)$} \\
\hline & & & & & & & lower & Upper \\
\hline Constant & 0.010 & 0.131 & .008 & 1 & .928 & 1.010 & & \\
\hline Qplsds & 0.979 & 0.151 & 52.908 & 1 & .000 & 2.754 & 2.097 & 3.502 \\
\hline Economicds & 1.250 & 0.183 & 79.544 & 1 & .000 & 3.373 & 2.547 & 4.372 \\
\hline Nsds & 0.652 & 0.110 & 22.243 & 1 & .000 & 1.986 & 1.478 & 2.361 \\
\hline Hds & 0.722 & 0.142 & 35.263 & 1 & .000 & 2. 805 & 1.612 & 2.962 \\
\hline Envds & 0.765 & 0.172 & 30.153 & 1 & .000 & 2. 605 & 1.604 & 2.896 \\
\hline
\end{tabular}




\begin{tabular}{lllllllll}
\hline Scds & 0.876 & 0.102 & 47.576 & 1 & .000 & 2.916 & 1.734 & 2.989 \\
\hline
\end{tabular}

Variables in the equation table, all factor scores are significant at $5 \%$ level of significance. Note that $\exp (\beta)$ gives the odds ratios for each variable. The odds ratio and confidence interval for economic domain is $3.373(95 \% \mathrm{CI}=2.547-4.372)$, for quality of public service was $2.754(95 \% \mathrm{CI}=2.097-3.502)$, neighborhood sanitation 1.986(95\% CI=1.478-2.361), for housing was $2.805(95 \% \mathrm{CI}=1.612-2.962)$, for environmental domain 2.605(95\% $\mathrm{CI}=1.604-2.896)$ and for social connectedness was $2.916(\mathrm{CI}=1.734-2.989)$. These indicate that with a one point increase on; quality of public service domain score, economic domain score, neighborhood sanitation domain score, housing domain score, environment domain score and social connectedness domain score is being associated with the odds of satisfying with life as whole increasing by a multiplicative factor $2.75,3.37,1.98,2.81,2.61$ and 2.92 respectively.

The result shows that satisfaction on the number of rooms is the most important predictor of housing satisfaction in the region. [18] and [21] in Hawassa reported that more rooms in a unit give housing satisfaction. Neighborhood sanitation is among the most important predictors of satisfaction with suitable living in the region. Similarly [23] reported that crime and sanitation is one of the most important predictor of quality of life in South Africa.

Factor analysis for the reduction of objective attributes One of the objectives of this study is to identify the dimensions of objective quality of life in selected zones of Amhara national region state. There are several objective attributes that may affect quality of life.

The data set was checked and it met the criteria for Bartlett's Test of Sphericity, since the P value (.000) is less than the test of significance $(\alpha=.05)$ and the Kaiser-Meyer-Olkin (KMO) measure of sampling adequacy is 0.870 which is greater than 0.7 indicating that there are probably significant relationships among attributes of the objective QOL (OQOL) and this in turn implies that the data set is suitable for factor analysis (Table 19). Six factors with eigen values greater than 0.9 were extracted in the study. Both the scree plot and the eigen values support the conclusion that these 15 attributes can be reduced to six components. The scree plot flattens out after the sixth component (Figure 2). The result of the factor analysis is presented in Table 20. Attributes with factor loadings of greater than 0.5 are considered in identifying the dimensions.

Table 19. The KMO and Bartlett's Test for the reduction of objective attributes.

\begin{tabular}{lll}
\hline Kaiser-Meyer-Olkin Measure of Sampling Adequacy & $\mathbf{0 . 8 7 0}$ \\
\hline \multirow{3}{*}{ Bartlett's Test of Sphericity } & Approx. Chi-Square & 2818.157 \\
& Degrees of freedom & 105 \\
& Sig. & .000 \\
\hline
\end{tabular}

The factors that are shown in Table 20 can be considered as dimensions of objective quality of life in Amhara national regional state. The five factors explain $77.62 \%$ of the total variation in the data set. The first factor explains $22.12 \%$, the second explains $18.86 \%$, the third explains $19.93 \%$, the forth factor explains $11.65 \%$ and the fifth and the sixth factors explain $8.49 \%$ and $6.82 \%$ respectively, of the total variation in the data set.

A comparison between the variables (attributes) of the six factors and the attributes of domains of life for the objective part of the household survey and the physical meaning for the first up to the six dimensions of objective QOL loading factors are: socio-economic, access to public service, access to education, housing, religious (spirituality) and length of residency respectively.

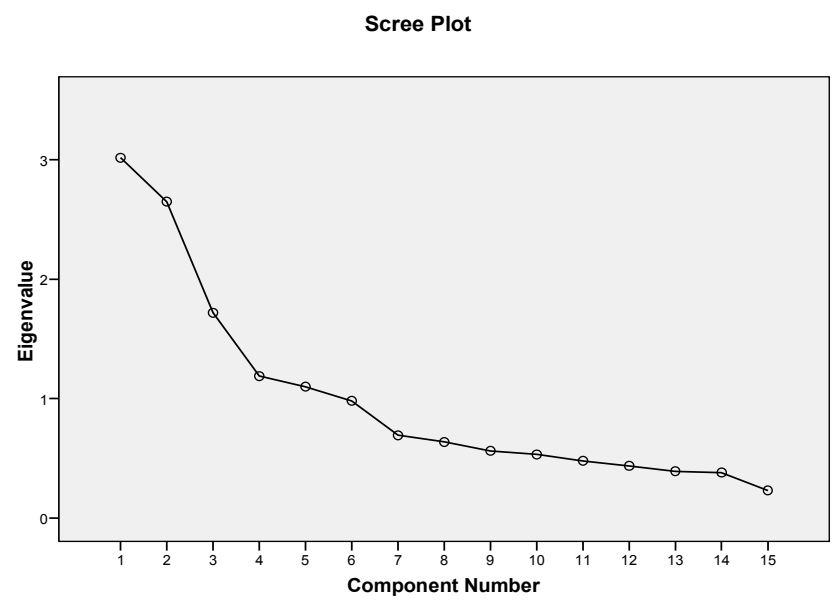

Fig. 2. Scree Plots of for the Reduction of Objective Attributes.

Table 20. Factor Loading Matrix for the Reduction of Objective Attributes.

\begin{tabular}{|c|c|c|c|c|c|c|}
\hline \multirow{2}{*}{ Objective attributes } & \multicolumn{6}{|c|}{ Factors } \\
\hline & 1 & 2 & 3 & 4 & 5 & 6 \\
\hline household size & 0.937 & & & & & \\
\hline number of dependent person & 0.872 & & & & & \\
\hline educational level & -0.825 & & & & & \\
\hline family income & -0.792 & & & & & \\
\hline distance of the house from police station & & 0.811 & & & & \\
\hline distance of the house from health care facility & & 0.789 & & & & \\
\hline distance of the house from main shopping area & & 0.751 & & & & \\
\hline distance of the house from secondary school & & & 0.891 & & & \\
\hline distance of the house from primary school & & & 0.868 & & & \\
\hline household tenure & & & & -0.917 & & \\
\hline number of rooms & & & & 0.893 & & \\
\hline
\end{tabular}




\begin{tabular}{|c|c|c|c|c|c|c|}
\hline \multirow{2}{*}{ Objective attributes } & \multicolumn{6}{|c|}{ Factors } \\
\hline & 1 & 2 & 3 & 4 & 5 & 6 \\
\hline distance of the house from spiritual place & & & & & 0.843 & \\
\hline frequency of church(mosque) attendance & & & & & -0.836 & \\
\hline years in Amhara region & & & & & & 0.876 \\
\hline Age & & & & & & 0.731 \\
\hline Eigen value & 3.62 & 3.43 & 2.87 & 2.31 & 1.45 & .996 \\
\hline Percentage of variance explained & 22.12 & 18.93 & 15.93 & 11.65 & 8.49 & 6.82 \\
\hline Percent total variance explained & 77.62 & & & & & \\
\hline
\end{tabular}

Extraction Method: Principal Component Analysis, Rotation Method: Varimax with Kaiser Normalization, Rotation converged in 6 iterations.

Binary logistic regression of overall relation between QOL and ODS Binary logistic regression is also applied to assess the relationship between overall quality of life which is dichotomized response variable (unsatisfied/satisfied) and domain scores which are obtained from the factor analysis of objective attributes. SPSS version 16 is used to perform binary logistic regression by making the unsatisfied level as reference category. Before applying the final multiple logistic regression models with 5 covariates for the intended purpose it has to be assessed and diagnosed for all possible model inadequacies

Assessing Model Fit Table 21 shows the non-significance of the chi-square value. Hence, no evidence to reject the null hypothesis that there is no difference between the observed and expected frequencies which indicates that the model adequately fits the data.

Table 21. Hosmer and Lemeshow Test for the Relationship between Overall QOL and Objective Domain Scores (ODS).

\begin{tabular}{llll}
\hline Step & Chi-square & Df & Sig. \\
\hline 1 & 8.620 & 8 & .637 \\
\hline
\end{tabular}

Table 22. Variables not in the Equation for the Relationship between Overall QOL and $O D S$.

\begin{tabular}{lllll}
\hline & Score & df & Sig. \\
\hline Variables & Sceconomic & 135.410 & 1 & .000 \\
& Acedu & 8.830 & 1 & .000 \\
& Housing & 27.929 & 1 & .001 \\
& Religion & 17.491 & 1 & .000 \\
& Acplds & 4.160 & 1 & .462 \\
& Length & 11.418 & 1 & .002 \\
Overall Statistics & 183.174 & 6 & .000 \\
\hline
\end{tabular}

The above able shows that the five factor out of the six factor scores (socio-economic status, access to education, housing, religion and length of residence) are individually significant predictors of whether respondents would be satisfied or not with their quality of life. But it is found that access to public service is not significant predictor of quality of life. This contradicts with the result of [25] who reported that the provision of public services have great influence on urban quality of life. The non significance of access of public service in this study may be related to the respondent's falsity in knowing the exact distance of their house from different public services. Higher the score in these dimensions, the lower is the quality of life.

Table 23. Omnibus Tests Coefficients for the Relationship between Overall $Q O L$ and $O D S$.

\begin{tabular}{llll}
\hline & Chi-square & Df & Sig. \\
\hline Step & 215.182 & 6 & .000 \\
Block & 215.182 & 6 & .000 \\
Model & 215.182 & 6 & .000 \\
\hline
\end{tabular}

The Omnibus Tests of Model Coefficients table indicates that, when we consider all six predictors together, the Model or equation is significant at $5 \%$ level of significance (chi-square 215.182.df $=6, \mathrm{p}<.05$ )

Table 24. Model Summary for the Relationship between QOL and ODS.

\begin{tabular}{llll}
\hline Step & $\mathbf{2}$ Log likelihood & $\begin{array}{l}\text { Cox \& Snell R } \\
\text { Square }\end{array}$ & Nagelkerke R Square \\
\hline 1 & 592.530 & .375 & .596 \\
\hline
\end{tabular}

The Model Summary table shows that $59.6 \%$ of the variance in whether or not respondents are satisfied with their life as whole can be predicted from a linear combination of the five independent variables.

Table 25. Classification Table for the Relationship between overall QOL and ODS.

\begin{tabular}{lllll}
\hline \multirow{2}{*}{ Observed } & \multicolumn{2}{l}{ Predicted } & \\
\cline { 3 - 4 } & & Overall Quality of Life & Percentage \\
\cline { 2 - 4 } & & Unsatisfied & Satisfied & Correct \\
\hline Quality of Life & Unsatisfied & 309 & 120 & 84.9 \\
Score & Satisfied & 83 & 297 & 80.5 \\
Overall Percentage & & & 82.7 \\
\hline
\end{tabular}

Note from the classification table that, overall, $82.7 \%$ of the participants were predicted correctly. The independent / covariate variables were better at helping us predict who would not be satisfied ( $80.5 \%$ correct) than at who would be satisfied $(82.7 \%$ correct $)$.

From the results of the classification table, Hosmer and Lemeshow test and model summary table, we can conclude that the fitted model with 11 covariates is satisfactory. The multiple logistic regression coefficients can be estimated using the maximum likelihood estimation method implemented in the SPSS package. The results are displayed in Table 26

Table 26. Variables in the Equation for the Relationship between overall QOL and ODS.

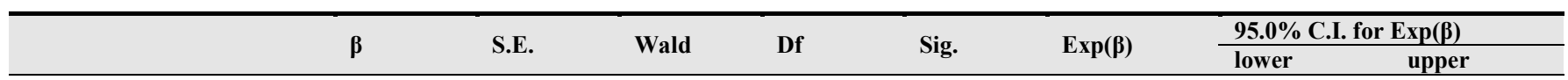




\begin{tabular}{|c|c|c|c|c|c|c|c|c|c|}
\hline & & \multirow{2}{*}{$\beta$} & \multirow{2}{*}{ S.E. } & \multirow{2}{*}{ Wald } & \multirow{2}{*}{ Df } & \multirow{2}{*}{ Sig. } & \multirow{2}{*}{$\operatorname{Exp}(\beta)$} & \multicolumn{2}{|c|}{ 95.0\% C.I. for $\operatorname{Exp}(\beta)$} \\
\hline & & & & & & & & lower & upper \\
\hline \multirow{7}{*}{ Step } & Constant & -0.126 & 0.120 & 0.656 & 1 & .555 & 0.950 & & \\
\hline & socioeconomic & -1.106 & 0.102 & 95.722 & 1 & .000 & 0.344 & 0.284 & 0.379 \\
\hline & Acplds & -0.127 & 0.160 & 2.680 & 1 & .160 & 0.824 & 0.638 & 1.073 \\
\hline & Acedu & -0.279 & 0.130 & 8.383 & 1 & .002 & 0.734 & 0.670 & 0.990 \\
\hline & Housing & -0.572 & 0.160 & 29.625 & 1 & .000 & 1.936 & 1.545 & 2. 860 \\
\hline & Religion & 0.398 & 0.170 & 16. 563 & 1 & .001 & 0.777 & 0.566 & 0.942 \\
\hline & Length & 0.412 & 0.180 & 18.116 & 1 & .000 & 1.245 & 1.024 & 1.989 \\
\hline
\end{tabular}

Table 26 shows that five factor scores out of six are significant at $5 \%$ level of significance. Note that $\operatorname{Exp}(\beta)$ gives the odds ratios for each variable. The odds ratio and confidence interval for socio-economic status $0.344(95 \% \mathrm{CI}=$ 0.284-0.379), for access to education $0.734 \quad(95 \%$ $\mathrm{CI}=0.670-0.990)$, for housing was $1.936(95 \%$ $\mathrm{CI}=1.545-2.860)$, for access for religious place $0.777(95 \%$ $\mathrm{CI}=0.566-0.942$ ) and length of residency was $1.245(\mathrm{CI}$ $=1.024-1.989)$. The values for instance indicate that with a one point increase in: distance of religious place domain score and length of residency domain score is being associated with the odds of satisfying with life as whole increasing by a multiplicative factor 0.777 and 1.225 respectively. On the other hand, a one unit change in the independent variable (socio-economic status domain score, distance of educational centers domain score, housing domain score) increase the odds of being satisfied with their life as whole by0.344, 0.734 and 1.936 respectively. That is dissatisfaction on overall quality of life is associated with travelling long to get educational centers and religious place. Having large number family size and number of dependent person is also associated with low quality of life.

The result shows that all of the six domains are significant predictors of quality of life in the region. And all of the six domains have positive impact on quality of life. For instance the higher the score in economic domain, the better is the people's quality of life in the region.

The fifteen variables are reduced to six independent factors which constitute $77 \%$ of the total variation in the original data set. The factors are named as socio-economic domain score, access to education domain score, housing domain score, spirituality domain score, access to public service domain score and immovability domain score. Elsa (2009) identified five dimensions using 13 attributes for Krikos sub city of Addis Abeba. These dimensions are crowdedness, socio-economic, safety and proximity, housing and demographic. Most of the dimensions is related to the dimensions obtained from this study. Das (2008) also identified seven dimensions of objective quality of life for the city of Guwahati using 27 attributes.

\section{Conclusion and Recommendations}

\subsection{Conclusions}

This paper tried to analyze the influence of both subjective attributes and objective attributes on zones quality of life in Amhara region. Ordinal logistic regression to explain the different aspects of quality of life such as housing satisfaction, quality of public service satisfaction, neighborhood sanitation satisfaction and safety satisfaction as well as an overall valuation of quality of life. The result of the study leads to conclude that satisfaction with number of rooms, attractiveness of the living place and crime in the neighborhood have strongest impact on housing domain satisfaction, built environment domain satisfaction and neighborhood safety domain satisfaction respectively. The attributes that has strongest impact on quality of public service and neighborhood sanitation are satisfaction on reliability of water service, and the beauties of streets and buildings in the neighborhood respectively. More over satisfaction on relative income, clothing cost and family relationship are found to be attributes that most explain the levels of satisfaction with family income, cost of living and social connectedness respectively.

Quality of public service domain, economic domain, neighborhood safety and security domain, Housing domain, environmental domain and social connectedness domain are identified as dimensions of subjective quality of life of the people selected zones in the region. All of the domain scores are found to be significant predictors of the people's quality of life. The higher the score in the above domains, the better is the people's quality of life exists.

Socio-economic domain, access to public service domain, access to education domain, housing domain, religious (spirituality) domain and length of residency domains are found to be the dimensions of the objective quality of life of the people selected zones in the region. Finally, we directly considered all the objective domain scores to explain quality of life and it is found that Socio-economic domain, distance to educational centers, housing, religion and immovability are significant predictors of quality of life. But access to public service is not significant predictor of quality of life of the people selected zones in the region. Religion and length of residency have positive impact on quality of life which implies that the higher the score in Religion and immovability, the better the quality of life. Socio-economic, access to education and housing has negative contribution to quality of life. The higher the score in these dimensions, the lower is the quality of life exists.

\subsection{Recommendation}

From the study it is found that housing satisfaction, neighborhood sanitation, economic aspect, neighborhood safety, access to education, quality of public services selected zones in the region, and socio-economic is some of the factors that may affect the quality of life of individuals selected zones 
in the region. Therefore regional planners and administrators should be aware of the fact that the people's quality of life satisfaction can be enhanced; by promoting home ownership, by improving the quality and quantity of governmental and non- governmental services in the region, by facilitating conditions so that peoples can reside without any sanitation problems, by stabilizing the market so that peoples can get goods and services with comparable cost, etc. Individually, quality of life in urban living can also be enhanced by building smooth relation with family and neighbors, by limiting family sizes, by having stable life in the region etc. Furthermore, in order to increase the level of Quality of Life in the region, the physical quality of the built environment should be improved by the supports of local and governmental authorities. Additionally, self and environmental consciousness should be increased in order to orient this people to take advantage of the community activities and social connectedness taking place in the area.

Generally, urban quality of life approach intends to create a healthy zonal city and provide suitable urban services for all, in the framework of sustainability. So in a healthy zonal city with a high quality of life, physical and socio-economic conditions are prepared to empower urban resident to flourish their capacities. Promoting quality of life therefore means investing in conditions guaranteeing people the capacity to broaden their opportunities for choosing their lifestyles and meeting their needs and preferences.

Finally, the findings and approaches of this study can be used in designing future urban QOL studies in the region. So we recommend similar studies with additional domains of life in the same or different areas in general so as to provide complete and useful insight for formulating appropriate policies.

\section{Authors' Contributions}

GT and ND wrote the proposal, designed the study, performed the statistical analysis, interpreted the results and finalized the manuscript. HZ, WK and TM participated in proposal writing, designed the study, coordinated data collection and supervised data entry. They also made critical review of the draft and final manuscript. All authors have read and agreed on the submitted manuscript.

\section{References}

[1] Ali A. Al-subaihi, (2003)."Sample size determination influencing factors and calculation strategies for survey research" 24(4):323-330.

[2] Aklilu K. and Dessalegne R. (2000). Listening to the Poor. AA: FSS. An assessment of quality of life in residential environments; case of selimiye quarter in Cyprus. Wikipedia, (http://en.wikipedia.org/wiki/Quality_of_life), 4June 2007.

[3] Andrews, F. M., \&Withey, S. B. (1976). "Social indicators of well-being: American's perception of life quality". New York: Plenum Press.

[4] Aweke A. (2010). "Statistical analysis of health related quality of life of HIV/patients on ART in Hawassa University Re feral Hospital; a comparative study to the general population", $M S c$ thesis.

[5] Azahan A., (2009) "The Quality of Life in Malaysia's Intermediate City:" Urban Dwellers Perspective; European Journal of Social Sciences.

[6] Bradshaw, Y.W., and Fraser, E. (1989), "City size, economic development and quality of life inChina:" New Empirical Evidence.

[7] Carlos M., (2008). "Quality of Life in Urban Neighborhoods in Colombia": The Cases of Bogotá and Medellín.

[8] Chung, Cambell A., Converse P., and Rodgers W.( 2003), "The quality of American life"; perception, Evaluation and satisfaction. Russell sage foundation, New York.

[9] Cochran, W.G., 1977. "Sampling Techniques; Third edition." John Wiley and sons (ASIA) pte Ltd., Singapore.

[10] Cummins, R. (2000). "Objective and subjective quality of life:" An interactive model. Social Indicators Research, 52, 5-72

[11] Diener, E. and Suh, E. (1997). "Measuring quality of life: economic, social, and subjective indicators," Social Indicators Research, 40, pp. 189-216.

[12] Elsa Sereke, (2009)."Urban quality of life and its spatial distribution in Addis abeba; krikos sub city". Msc thesis.

[13] Genanew T. (2011) "Statistical Analysis of Saving Habits of Employees: A Case Study at Debre Birhan Town in North Shoa, Ethiopia" MSc. Thesis.

[14] Gilhooly, M., Gilhooly, K. and Bowling, A. (2005), "Quality of life": Meaning and measurement.

[15] Habtamu W. (2004), "Quality of Life, Poverty and Inequality in Ethiopia".

[16] Hosmer and Lemshow, (1989). "Applied logistic regression". John Wiley and sons. New York.

[17] Luis D. \& Isabel. Paula B., (2007).” Measuring Subjective Quality of Life: A Survey to Porto's Residents" Applied Research in Quality of Life 2:51-64.

[18] Luis J., Róger M. \& Juan R.(2008)" Quality of Life in Urban Neighborhoods in Costa Rica"Research Network Working Papers; R-563.

[19] McCullagh, P. (1980), "Regression Models for Ordinal Data," Journal of the Royal Statistical Society, Series B (Methodological), 42, 109-142.

[20] Natnael M. (2011) "Statistical Analysis of Urban Quality of Life -The Case of Hawassa City" MSc. Thesis.

[21] Rashida H. (2009,)"Measuring Human Wellbeing in Pakistan: Objective Versus Subjective Indicators", European Journal of Social Sciences.

[22] Ricardo R. (2010),"Measuring subjective quality of life in Macao"; application of international well being index.

[23] Sedigheh L. and Karim S.(2009),"An assessment of Urban Quality of Life by Using Analytic Hierarchy Process Approach": AComparative Study of Quality of Life in the North of Iran, ISSN 1549-3652. 
[24] Sedigheh L., Amin F., Husain H. and Ahmad P., (2011). "A Study of Urban Quality of Life in a Developing Country" Journal of Social Sciences 7 (2): 232.

[25] Stanislav K., (1998). "The Methods of the Quality of Life Assessment" masters degree thesis.
[26] Tauhidur R., (2005). "Measuring the Quality of Life across Countries"; A Sensitivity. 